03,13

\title{
Структура и свойства композитов на основе нитридов алюминия и галлия, выращенных на кремнии разной ориентации с буферным слоем карбида кремния
}

\author{
(C) Ш.Ш. Шарофидинов ${ }^{1,2}$, С.А. Кукушкин ${ }^{2}$, М.В. Старицын ${ }^{3}$, А.В. Солнышкин ${ }^{4}$, \\ О.Н. Сергеева ${ }^{4}$, Е.Ю. Каптелов ${ }^{1}$, И.П. Пронин ${ }^{1}$ \\ ${ }^{1}$ Физико-технический институт им. А.Ф. Иофффе, \\ Санкт-Петербург, Россия \\ ${ }^{2}$ Институт проблем машиноведения РАН, \\ Санкт-Петербург, Россия \\ ${ }^{3}$ НИЦ „Курчатовский институт“ - ЦНИИ Конструкционных материалов „Прометей“ им. И.В. Горынина, \\ Санкт-Петербург, Россия \\ ${ }^{4}$ Тверской государственный университет, \\ Тверь, Россия \\ E-mail: sergey.a.kukushkin@gmail.com
}

Поступила в Редакцию 30 декабря 2021 г.

В окончательной редакции 30 декабря 2021 г.

Принята к публикации 3 января 2022 г.

Исследованы микроструктура и пироэлектрические свойства композитных эпитаксиальных слоев $\mathrm{Al}_{x} \mathrm{Ga}_{1-x} \mathrm{~N}$, выращенных на гибридных подложках $\mathrm{SiC} / \mathrm{Si}(111)$ и $\mathrm{SiC} / \mathrm{Si}(110)$ методом хлорид-гидридной эпитаксии. Обнаружено явление самопроизвольного, в процессе роста слоев, образования системы гетеропереходов, состоящих из периодических расположенных перпендикулярно направлению роста слоев $\mathrm{Al}_{x} \mathrm{Ga}_{1-x} \mathrm{~N}$ различного состава. Измерения пирокоэффициентов этих гетероструктур показали, что вне зависимости от ориентации исходной подожки $\mathrm{Si}$ их пирокоэффициенты имеют близкие значения порядка $\gamma \sim(0.7-1) \cdot 10^{-10} \mathrm{C} / \mathrm{cm}^{2} \mathrm{~K}$. Показано, что для повышения величины пиротклика необходимо на поверхность $\mathrm{Al}_{x} \mathrm{Ga}_{1-x} \mathrm{~N} / \mathrm{SiC} / \mathrm{Si}$ наносить слой $\mathrm{AlN}$, толщиной превышающий $1 \mu \mathrm{m}$. Это приводит к рекордным, для кристаллов и пленок $\mathrm{AlN}$, значениям пирокоэффициента $\gamma \sim 18 \cdot 10^{-10} \mathrm{C} / \mathrm{cm}^{2} \mathrm{~K}$.

Ключевые слова: подложки карбида кремния на кремнии, хлорид-гидридная эпитаксия, эпитаксиальные слои $\mathrm{AlGaN}$, нитрид алюминия, нитрид галлия, пироэлектрические свойства.

DOI: $10.21883 /$ FTT.2022.05.52331.250

\section{1. Введение}

Широкозонные полупроводники на основе нитридов $(\mathrm{AlN}, \mathrm{GaN}, \mathrm{AlGaN})$ являются базовыми материалами для использования в фотонике глубокого ультрафиолета и создания высокоэффективных фотоприемников, светодиодов и лазеров нового поколения [1-7]. Для массового изготовления этих устройств требуется использование дешевых подложек, к которым относится кремний. Однако препятствием к использованию кремниевых подложек является сильное различие параметров решеток кремния и нитридов. Для преодоления такого различия в работах [8-10] был разработан метод замещения атомов формирование на кремниевой подложке нанометровых буферных слоев карбида кремния ( $\mathrm{SiC} /(111) \mathrm{Si})$, у которого параметры решетки отличаются от аналогичных параметров гексагонального AlN менее чем на 1\%. Это позволило получать высококачественные эпитаксиальные слои AlN на подложках $\mathrm{SiC} /(111) \mathrm{Si}$ методом хлоридгидридной эпитаксии (ХГЭ), характеризующимся высокой скоростью роста $[11,12]$. Для получения на таких подложках эпитаксиальных слоев $\mathrm{GaN}$, снижения в них механических напряжений и уменьшения числа дислока- ций целесообразно формировать переходные слои твёрдых растворов $\mathrm{Al}_{x} \mathrm{Ga}_{1-x} \mathrm{~N}[2-7,13]$. Было показано, что использование переходных слоев $\mathrm{Al}_{x} \mathrm{Ga}_{1-x} \mathrm{~N}$ позволяет получать монокристаллы $\mathrm{GaN}$ методом ХГЭ приемлемого кристаллического качества толщиной в несколько сотен микрон на подложках $\mathrm{SiC} /(111) \mathrm{Si}$, сравнимого по качеству с монокристаллическими слоями, полученными методом ХГЭ при гомоэпитаксии на „родных“ подложках $\mathrm{GaN}[14,15]$. Это позволяет расширить области применения широкозонных нитридных материалов и в ближайшем будущем приступить к созданию на их основе силовой электроники нового поколения, совместимой с кремниевой электроникой.

Вместе с тем, наличие полярной оси, высоких значений спонтанной поляризации и пьезоэлектрических (электромеханических) параметров в нитридах алюминия и галлия позволяет использовать их для создания целого спектра микроэлектромеханических преобразователей - от приемно-передающих акустических устройств, актюаторов, сенсоров и т.д., до разнообразных СВЧ-устройств - генераторов, линий задержки, фильтров, которые могут функционировать в ши- 



Рис. 1. РЭМ-изображения торцевых сколов гетероструктур $\mathrm{Al}_{x} \mathrm{Ga}_{1-x} \mathrm{~N}$, сформированных на подложках $\mathrm{SiC} /(110) \mathrm{Si}$ (№ 1 и 2$)$ и $\mathrm{SiC} /(111) \mathrm{Si}$ (№ 3 и 4).

роком интервале температур. По своим электромеханическим и пироэлектрическим характеристикам эти материалы конкурентоспособны с традиционными сегнетоэлектрическими материалами, такими как твердые растворы цирконата-титаната свинца, ниобат и танталат лития [16-23]. Полярные свойства твердых растворов нитридов галлия и алюминия $-\mathrm{Al}_{x} \mathrm{Ga}_{1-x} \mathrm{~N}$ с различным элементным соотношением $\mathrm{Al}$ и $\mathrm{Ga}$ до настоящего времени практически не были исследованы. Интерес к этим материалам определяется тем, что они могут сочетать как высокую спонтанную поляризацию и электромеханические свойства, присущие нитриду алюминия, так и высокие пироэлектрические параметры, обнаруженные у нитрида галлия. Препятствие к исследованию полярных свойств таких структур определяется их низкоомностью, вызванной высокой концентрацией как точечных, так и протяженных дефектов структуры.

В последнее время, наряду с уже традиционными методами выращивания гетероструктур, какими являются методы молекулярно-лучевой эпитаксии (МЛЭ), металлорганической газофазной эпитаксии (МОГФЭ), сублимационного роста и т.д., происходило активное исследование роста эпитаксиальных слоев $\mathrm{AlGaN}$ на подложках $\mathrm{SiC} / \mathrm{Si}$ методом ХГЭ [24]. В последнем случае предполагается, что использование подложек с другой ориентацией может приводить к меньшим механическим напряжениям в тонких слоях нитридов и к уменьшению концентрации дефектов. Это, в свою очередь, позволит получать на основе эпитаксиальных слоев $\mathrm{AlGaN}$ достаточно высокоомные гетероструктуры, на которых будет возможным изучение их полярных свойств [25]. Целью настоящей работы являлось исследование связи полярных свойств с микроструктурой и составом гетероструктур на основе эпитаксиальных слоев $\mathrm{AlGaN}$, выращенных на поверхности наноразмерного $\mathrm{SiC}$, сформированного методом согласованного замещения атомов [8-10] на кремниевых подложках двух ориентаций, а именно на поверхности $\mathrm{Si}$ (111) и поверхности $\mathrm{Si}(110)$.

\section{2. Методы и объекты исследования}

Для исследования были отобраны несколько гетероструктур $\mathrm{AlGaN}$, эпитаксиально выращенных методом ХГЭ на подложках $\mathrm{SiC} /(111) \mathrm{Si}$ и $\mathrm{SiC} /(110) \mathrm{Si}$, на которых оказалось возможным провести измерения диэлектриче- 

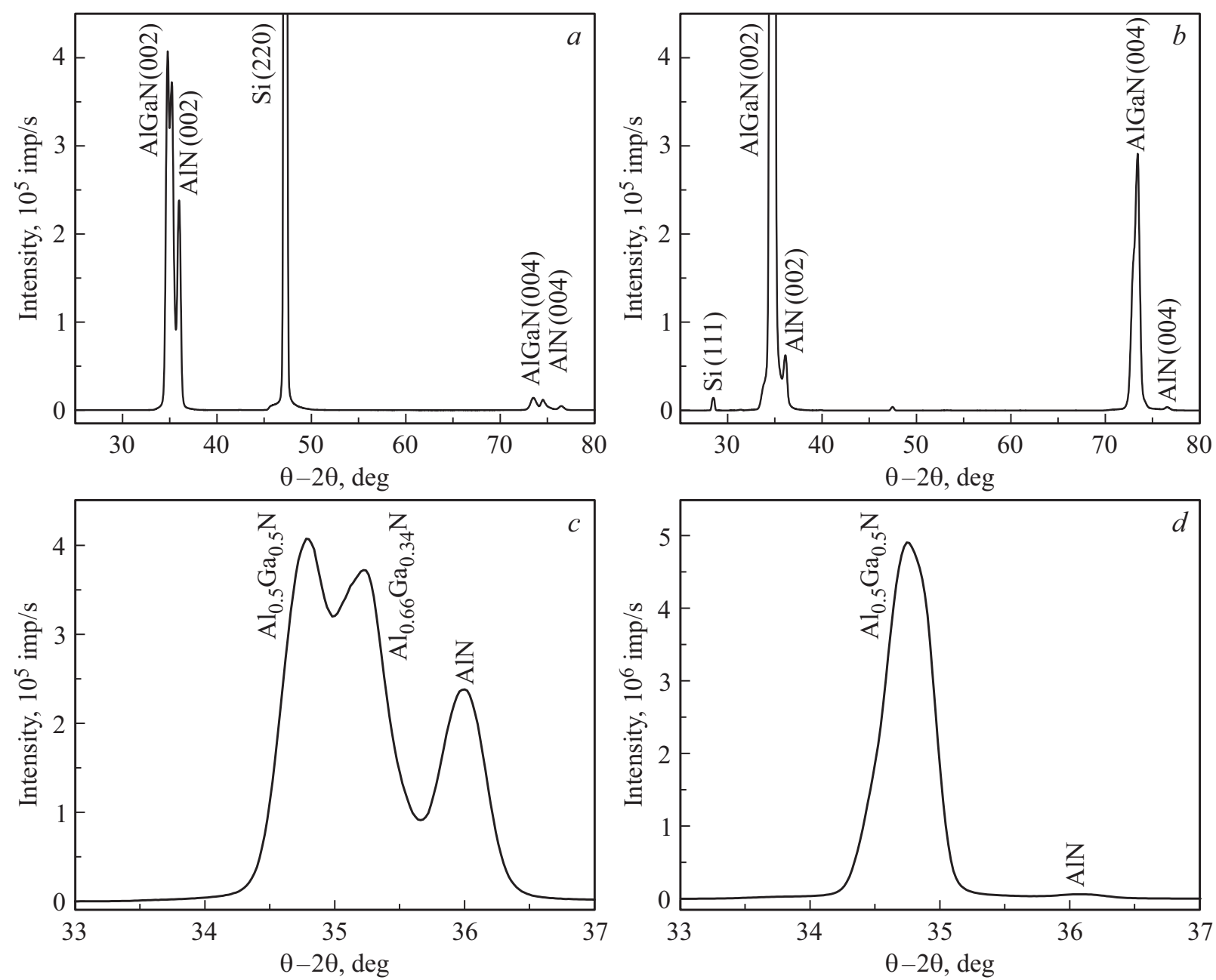

Pис. 2. Дифрактограммы $\theta-2 \theta$ гетероструктур $\mathrm{AlGaN}$ (образцов № 1 и 3 ), выращенных на подложках $\mathrm{SiC} /(110) \mathrm{S}$ (a,c) и $\mathrm{SiC} /(111) \mathrm{Si}(b, d)$.

ского и пироэлектрического откликов. Технология роста эпитаксиальных слоев $\mathrm{AlGaN}$ описана в работах $[13,24]$. Во всех случаях толщина буферного слоя $\mathrm{SiC}$ не превышала $90 \mathrm{~nm}$.

Микроструктурные изображения поверхности и торцевых сколов образцов $\mathrm{AlGaN} / \mathrm{SiC} / \mathrm{Si}(111)$ и $\mathrm{AlGaN} / \mathrm{SiC} / \mathrm{Si}(110)$ были получены с помощью метода растровой электронной микроскопии (РЭМ) на установке LIRA 3 (Tescan). Для определения состава гетероструктур использовался метод электроннозондового рентгеновского микроанализа, реализованный на энергодисперсионной приставке X-Max (Oxford Instruments). Энергия зондирующего электронного пучка составляла $12 \mathrm{keV}$. Кристаллическая структура образцов контролировалась методом рентгеноструктурного анализа $\theta-2 \theta$ (Rigaru, Ultima IV). Для проведения электрофизических измерений на тыльную сторону кремниевой подложки наносился платиновый электрод, a со стороны $\mathrm{AlGaN}$ на поверхности гетероструктур формировались платиновые контактные площадки размером $1 \times 1 \mathrm{~mm}$.
Для возбуждения динамического пироэлектрического отклика использовался лазерный модуль CLM-18451R-980 $(\lambda=980 \mathrm{~nm})$, тепловой поток которого мощностью $220 \mathrm{~mW}$ модулировался в диапазоне частот $1-1000 \mathrm{~Hz}$ [23].

Первые два образца (№ 1 и 2) представляли собой гетероструктуры, выращенные на подложке $\mathrm{SiC} /(110) \mathrm{Si}$. Образец № 1 представлял собой комбинацию, состоящую из последовательно выращенных слоев AlN и $\mathrm{AlGaN}$, каждый толщиной $\sim 0.8 \mu \mathrm{m}$ (рис. $1, a$ ). Образец № 2 состоял из повторяющихся тонких $(70 \mathrm{~nm}$ и менее) слоев $\mathrm{AlGaN} \mathrm{c} \mathrm{переменным} \mathrm{составом.} \mathrm{Причем}$ состав изменялся от подложки к поверхности слоя. Вначале рос слой практически чистого $\mathrm{GaN}$ с содержание $\mathrm{GaN}$, равным приблизительно 95 at.\%. Затем, по мере увеличения толщины, слой все более и более обогащался Al. По достижению слоем толщины, приблизительно равной $1.1 \mu \mathrm{m}$, произошло резкое изменение состава слоя. Это хорошо видно по изменению контраста (темная полоса) на рис. 1, $b$. После этого, в слое $\mathrm{AlGaN}$ начал преобладать Al. Самые верхние 

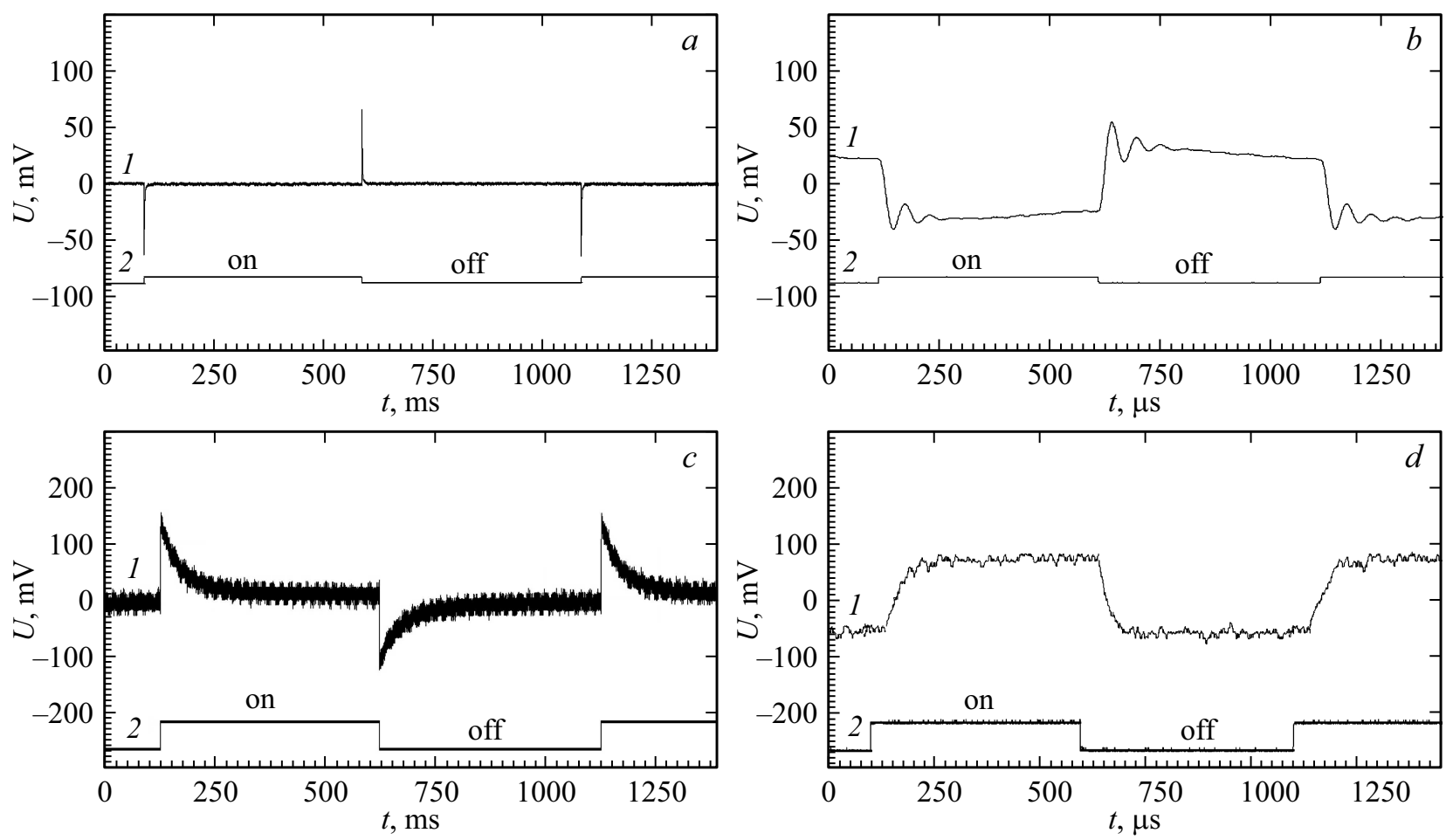

Рис. 3. Пироэлектрический отклик (кривые 1 ) образцов № 2 и 4, полученных на частотах $1 \mathrm{~Hz}(a, c)$ и $1 \mathrm{kHz}(b, d)$. Стробы $(2)$ иллюстрируют модулированный тепловой поток.

слои состояли практически из чистого AlN с небольшим содержанием $\mathrm{GaN}$.

Вторая группа образцов (№ 3 и 4) была выращена на подложке $\mathrm{SiC} /(111) \mathrm{Si}$. Образец № 3 состоял из нескольких чередующихся слоев $\mathrm{AlGaN}$ с различным элементным соотношением $\mathrm{Al} / \mathrm{Ga}$ общей толщиной $\sim 7.3 \mu \mathrm{m}$ (рис. 1,c). Образец № 4 отличался от последнего тем, что на аналогичной многослойной структуре $\mathrm{AlGaN}$ (общей толщиной $\sim 16 \mu \mathrm{m}$ ) был сформирован толстый $(\sim 200 \mu \mathrm{m})$ слой $\mathrm{AlN}$ (рис. $1, d)$.

\section{3. Экспериментальные результаты и их обсуждение}

В соответствии с данными рентгеноструктурного анализа $(\theta-2 \theta)$ ростовая ориентация гетероструктур $\mathrm{AlGaN}$, выращенных на подложке $\mathrm{SiC} /(110) \mathrm{Si}$, соответствовала гексагональной полярной оси [002] (рис. 2,a). На выделенном участке дифрактограммы образца № 1 рефлекс, расположенный в области $2 \theta=36^{\circ}$, соответствует нижнему слою состава, близкого к нитриду алюминия (рис. 2,c). Верхнему слою $\mathrm{AlGaN}$ соответствуют два хорошо различающихся на рисунке рефлекса. Они соответствуют двум составам AlGaN (1) $\mathrm{Al} / \mathrm{Ga}=0.50 / 0.50$ и (2) $\mathrm{Al} / \mathrm{Ga} \approx 0.67 / 0.33$. Данные по составу слоя $\mathrm{AlGaN}$, определенные по положению рефлексов на дифрактограмме, хорошо коррелируют с данными, полученными методом электронно-зондового рентгеновского микроанализа. РЭМ-изображения поверхности образца показали, что имеется два типа областей, отличающихся величиной шероховатости. Одна область, ответствующая составу (1), имеет низкую шероховатость поверхностности, а другая область, отвечающая составу (2) - высокую. По всей видимости, на рост $\mathrm{AlGaN} \mathrm{c} \mathrm{различным} \mathrm{элементным} \mathrm{соотношением}$ $\mathrm{Al} / \mathrm{Ga}$ оказывает существенное влияние качество подслоя карбида кремния в разных областях подложки.

Рентгенограмма гетероструктуры $\mathrm{AlGaN}$ (образца № 3), сформированной на подложке $\mathrm{SiC} /(111) \mathrm{Si}$, представлена на рис. 2,b,d. Слабый рефлекс при $2 \theta \approx 36^{\circ}$, отвечает тонкому подслою нитрида алюминия, сформированному непосредственно на карбиде кремния. Уширенный рефлекс в области $2 \theta \approx 34.5-35^{\circ}$ может свидетельствовать о том, что на фоне слоев, соответствующих составу с соотношением $\mathrm{Al} / \mathrm{Ga}=0.5 / 0.5$, имеются прослойки состава $\mathrm{Al}_{x} \mathrm{Ga}_{1-x} \mathrm{~N}$ с большим содержанием алюминия. Гетероструктура образца № 4 преимущественно состояла из слоев, близких по составу к $\mathrm{Al}_{0.5} \mathrm{Ga}_{0.5} \mathrm{~N}$, с подслоями, как и в предыдущем случае, обогащенными атомами алюминия.

Анализ процессов образования прослоек (или периодической структуры $\mathrm{AlGaN}$ ), наблюдаемых ранее [24,25], свидетельствует о том, что такая структура является результатом самоорганизации состава и образования сложного композитного материала, по всей видимости, связанного с периодической релаксацией механических напряжений, накапливающихся в процессе роста гетероструктуры. Можно полагать, что изменение состава ком- 
позита сопровождается формированием гетеропереходов и системы встроенных объемных зарядов; последнее должно серьезно сказываться на проявлении диэлектрических и пироэлектрических свойств.

Формы пироэлектрического отклика гетероструктур (образцов № 2 и 4) на частотах $1(a, c)$ и $1000 \mathrm{~Hz}(b, d)$ представлены на рис. 3. Характер пироотликов образцов № 1 и 3 соответствовал форме и амплитуде откликов, характерных для образца № 2. Результаты измерения пирооткликов были получены в режиме регистрации электрического тока с использованием операционного усилителя.

Расчет пироэлектрического коэффициента, выполненный по формуле, представленной в работе [23], показал, что пироотклики (пирокоэффициенты , $\gamma^{6}$ ) гетероструктур AlGaN (образцов № 1,2 и 3) незначительно отличались друг от друга, а значения пирокоэффициента варьировались в диапазоне величин $\gamma \sim(0.7-1) \cdot 10^{-10} \mathrm{C} / \mathrm{cm}^{2} \mathrm{~K}$. Значительно выше оказался пироотклик гетероструктуры (образец № 4), состоящей из тонких слоев $\mathrm{AlGaN}$ и толстого слоя $\mathrm{AlN}$, показавший результат $\gamma \sim 18 \cdot 10^{-10} \mathrm{C} / \mathrm{cm}^{2} \mathrm{~K}$, т. е. практически в 20-25 раз выше, чем у многослойных слоев $\mathrm{AlGaN}$.

Крайне низкие значения пироэлектрического коэффициента, наблюдаемого на отличных друг от друга структурах $\mathrm{AlGaN}$, выращенных в направлении полярной оси [002] как на подложках $\mathrm{SiC} /(111) \mathrm{Si}$, так и $\mathrm{SiC} /(110) \mathrm{Si}$, по всей видимости, связаны с особенностями роста этих структур. Можно предположить, что рост каждого последующего подслоя происходит с изменением ориентации полярной оси в противоположном направлении. В этом случае воздействие теплового потока приводит к тому, что смещение зарядов в соседних слоях происходит навстречу друг другу, и результирующий регистрируемый пироэлектрический ток является результатом не сложения, а вычитания индуцированного тока каждого из подслоев. Подобный подход для многослойных нитридных структур был применен для объяснения существенного снижения величины пирокоэффициента в трехслойной структуре нитрида алюминия, выращенной непосредственно на подложке $\mathrm{SiC} /(111) \mathrm{Si}$ [26]. В отличие от образцов № 1-3, в образце № 4 за счет доминирования слоя нитрида алюминия, толщина которого составляла более 90\% толщины гетероструктуры, был получен один из лучших значений пирокоэффициента, достигнутых на эпитаксиальных слоях AlN.

\section{4. Заключение}

Таким образом, в настоящей работе были исследованы пиросвойства сложных композитных структур, состоящих из периодических расположенных перпендикулярно направлению роста слоев $\mathrm{Al}_{x} \mathrm{Ga}_{1-x} \mathrm{~N}$ различного состава, выращенных на гибридный подложках $\mathrm{SiC} / \mathrm{Si}(111)$ и $\mathrm{SiC} / \mathrm{Si}(110)$ методом ХГЭ. Гибридные подложки $\mathrm{SiC} / \mathrm{Si}(111)$ и $\mathrm{SiC} / \mathrm{Si}(110)$ были синтезированы но- вым методом согласованного замещения атомов. Измерения пирокоэффициентов этих гетероструктур показал, что вне зависимости от ориентации исходной подложки $\mathrm{Si}$ их пирокоэффициенты имеют близкие к друг другу значения порядка $\gamma \sim(0.7-1) \cdot 10^{-10} \mathrm{C} / \mathrm{cm}^{2} \mathrm{~K}$. Показано, что для повышения величины пиротклика необходимо на поверхность $\mathrm{Al}_{x} \mathrm{Ga}_{1-x} \mathrm{~N} / \mathrm{SiC} / \mathrm{Si}$ наносить слой $\mathrm{AlN}$, толщиной превышающей $1 \mu \mathrm{m}$. Оказалось, что дополнительное нанесение слоя AlN на поверхность гетероструктуры $\mathrm{Al}_{x} \mathrm{Ga}_{1-x} \mathrm{~N} / \mathrm{SiC} / \mathrm{Si}$ приводит к образованию новой композитной структуры $\mathrm{AlN} / \mathrm{Al}_{x} \mathrm{Ga}_{1-x} \mathrm{~N} / \mathrm{SiC} / \mathrm{Si}$, обладающей рекордными, для кристаллов и пленок $\mathrm{AlN}$, значениями пирокоэффициента $\gamma \sim 18 \cdot 10^{-10} \mathrm{C} / \mathrm{cm}^{2} \mathrm{~K}$.

\section{Финансирование работы}

Работа выполнена в рамках проекта Российского научного фонда № 20-12-00193.

Часть экспериментальных исследований выполнена на оборудовании Центра коллективного пользования научным оборудованием „Состав, структура и свойства конструкционных и функциональных материалов“ НИЦ „Курчатовский институт“ - ЦНИИ КМ „Прометей“.

Рост пленок $\mathrm{SiC}$ на $\mathrm{Si}$ был осуществлен с использованием оборудования УНУ „Физика, химия и механика кристаллов и тонких пленок“ (ФГУП ИПМаш РАН, Санкт-Петербург).

\section{Конфликт интересов}

Авторы заявляют, что у них нет конфликта интересов.

\section{Список литературы}

[1] S. Nakamura, T. Mukai, M. Senoh. Appl. Phys. Lett. 64, 1687 (1994).

[2] S. Guha, N.A. Bojarczuk. Appl. Phys. Lett. 72, 415 (1998).

[3] M. Kneissl, Zh. Yang, M. Teepe, C. Knollenberg, O. Schmidt, P. Kiesel, N.M. Johnson, S. Schujman, L.J. Schowalter. J. Appl. Phys. 101, 123103 (2007).

[4] S. Keller, C.S. Suh, Z. Chen, R. Chu, S. Rajan, N.A. Fichtenbaum, M. Furukawa, S.P. DenBaars, J.S. Speck, U.K. Mishra. J. Appl. Phys. 103, 033708 (2008).

[5] P. Dong, J.-C. Yan, J.-X. Wang, Y. Zhang, C. Geng, T.-B. Wei, P.-P. Cong, Y.-U. Zhang, J.-P. Zeng, Y.-D. Tian, L. Sun, Q.F. Yan, J.-M. Li, S.-F. Fan, Z.-X. Qin. Appl. Phys. Lett. 102, 241113 (2013).

[6] W. Guo, Z. Bryan, J.-Q. Xie, R. Kirste, S. Mita, I. Bryan, L. Hussey, M. Bobea, B. Haidet, M. Gerhold, R. Collazo, Z. Sitar. J. Appl. Phys. 115, 103108 (2014).

[7] K. Lee, R. Page, V. Protasenko, L.J. Schowalter, M. Toita, H.G. Xing, D. Jena. Appl. Phys. Lett. 118, 092101 (2021).

[8] С.А. Кукушкин, А.В. Осипов. ФТТ 50, 6, 1188 (2008).

[9] S.A. Kukushkin, A.V. Osipov. J. Phys. D 47, 31, 313001 (2014).

[10] С.А. Кукушкин, А.В. Осипов, Н.А. Феоктистов. ФТТ 56, 8 , 1457 (2014). 
[11] В.Н. Бессолов, Ю.В. Жиляев, Е.В. Коненкова, Л.М. Сорокин, Н.А. Феоктистов, Ш.Ш. Шарофидинов, М.П. Щеглов, С.А. Кукушкин, Л.И. Метс, А.В. Осипов. ПЖТФ 36, 11, 17 (2010).

[12] В.Н. Бессолов, Ю.В. Жиляев, Е.В. Коненкова, Л.М. Сорокин, Н.А. Феоктистов, Ш.Ш. Шарофидинов, М.П. Щеглов, С.А. Кукушкин, Л.И. Метс, А.В. Осипов. Опт. журн. 78, 7, 23 (2011).

[13] С.А. Кукушкин, Ш.Ш. Шарофидинов. ФТТ 61, 12, 2338 (2019).

[14] K. Fujito, Sh. Kubo, H. Nagaoka, T. Mochizuki, H. Namita, S. Nagao. J. Cryst. Growth 311, 10, 3011 (2009).

[15] J.A. Freitas, J.C. Culbertson, N.A. Mahadik, T. Sochacki, M. Iwinska, M.S. Bockowski. J. Cryst. Growth 456, 113 (2016).

[16] P. Muralt. Rep. Prog. Phys. 64, 1339 (2001).

[17] P. Muralt. J. Am. Ceram. Soc. 91, 5, 1385 (2008).

[18] M.S. Shur. Noise in devices and circuits III. Proc. SPIE, 5844, 248 (2005).

[19] С.Ю. Давыдов, О.В. Посредник. ФТТ 58, 4, 630 (2016).

[20] L. Natta, V.M. Mastronardi, F. Guido, L. Algieri, S. Puce, F. Pisano, F. Rizzi, R. Pulli, A. Qualtieri, M. De Vittorio. Sci. Rep. 9, 8392 (2019).

[21] O.N. Sergeeva, A.A. Bogomolov, A.V. Solnyshkin, N.V. Komarov, S.A. Kukushkin, D.M. Krasovitsky, A.L. Dudin, D.A. Kiselev, S.V. Ksenich, S.V. Senkevich, E.Yu. Kaptelov I.P. Pronin. Ferroelectrics 477, 121 (2015).

[22] G.E. Stan, M. Botea, G.A. Boni, I. Pintilie, L. Pintilie. Appl. Surf. Sci. 353, 1195 (2015).

[23] О.Н. Сергеева, А.В. Солнышкин, Д.А. Киселев, Т.С. Ильина, С.А. Кукушкин, А.В. Осипов, Ш.Ш. Шарофидинов, Е.Ю. Каптелов, И.П. Пронин. ФТТ 61, 12, 2370 (2019).

[24] С.А. Кукушкин, Ш.Ш. Шарофидинов, А.В. Осипов, А.С. Гращенко, А.В. Кандаков, Е.В. Осипова, К.П. Котляр, Е.В. Убыйвовк, ФТТ 63, 3, 363 (2021).

[25] А.В. Солнышкин, О.Н. Сергеева, О.А. Шустова, Ш.Ш. Шарофидинов, М.В. Старицын, Е.Ю. Каптелов, С.А. Кукушкин, И.П. Пронин. ПЖТФ 47, 20, 7 (2021).

[26] O.A. Shustova, O.N. Sergeeva, A.V. Solnyshkin, I.T. Zezianov, E.Yu. Kaptelov, I.P. Pronin, Sh.Sh. Sharofudinov, S.A. Kukushkin. Ferroelectrics (2022). В печати.

Редактор Ю.Э. Китаев 